\title{
Haplotypes of Tumor Necrosis Factor Gene and Tracheal Aspirate Fluid Levels of Tumor Necrosis Factor- $\alpha$ in Preterm Infants
}

\author{
S. NADYA J. KAZZI, GERARD TROMP, MICHAEL W. QUASNEY, AND IRINA A. BUHIMSCHI
}

\begin{abstract}
Departments of Pediatrics [S.N.J.K.], Center for Molecular Medicine and Genetics [G.T.], Wayne State University School of Medicine, Detroit, Michigan 48201; Department of Pediatrics [M.W.Q.], Medical College of Wisconsin, Milwaukee, Wisconsin 53226; Department of Obstetrics, Gynecology and Reproductive Sciences [I.A.B.], Yale University School of Medicine, New Haven, Connecticut 06520
\end{abstract}

\begin{abstract}
Individual variability in the production of tumor necrosis factor- $\alpha$ (TNF- $\alpha$ ) has been attributed to genetic factors. We examined whether alleles of TNF gene (lymphotoxin- $\alpha+250$, TNF$\alpha-308$, and TNF- $\alpha$-238) affect tracheal aspirate fluid (TAF) levels of TNF- $\alpha$ among preterm infants at risk of bronchopulmonary dysplasia. TAF samples were collected within $48 \mathrm{~h}$ of birth and 7, 14, 21, and $28 \mathrm{~d}$ later. Haplotypes [designated using the nucleotide bases in the chromosome order (lymphotoxin- $\alpha+250$, TNF- $\alpha-308$, TNF- $\alpha$ 238)] of TNF were correlated with levels of TNF- $\alpha$. Diplotypes of TNF (genotypes of haplotypes) classified as high, intermediate, or low based on their relation to TAF TNF- $\alpha$ levels were also correlated with TNF- $\alpha$ levels. The most frequent (and reference haplotype) was AGG. The GGG haplotype was associated with the lowest TAF TNF- $\alpha$ levels on day 7 among African American infants $(p<0.008)$. Sequential changes in levels of TNF- $\alpha$ correlated with infants' diplotype status [high (HH), intermediate (HL), low (LL)]. Fetal chorioamnionitis but not bronchopulmonary dysplasia was associated with infants' diplotypes $(p<0.005)$. Haplotypes of the TNF gene influence TAF levels of TNF- $\alpha$. Diplotypes of TNF are associated with fetal chorioamnionitis. (Pediatr Res 64: 165-170, 2008)
\end{abstract}

$\mathrm{P}$ rolonged elevations of several indices of inflammation have been documented in the tracheal aspirate fluid (TAF) of infants who develop bronchopulmonary dysplasia (BPD) (1). Tumor necrosis factor- $\alpha$ (TNF- $\alpha$ ) is one of the proinflammatory cytokines that is increased in the TAF of infants at risk of BPD (2). This cytokine plays a vital role in the regulation of inflammation because it affects the release of other proinflammatory cytokines such as IL-1, IL-6, and several other mediators of inflammation including itself (3). Excessive production of TNF- $\alpha$ may overwhelm counter-regulatory processes that are involved in containing the inflammatory response, and may lead to prolonged inflammation and underlying tissue damage $(4,5)$. Individual variability in the production of TNF was documented from family studies (6) and has been mostly attributed to inherited genetic factors (7). Production of TNF- $\alpha$ is regulated at the transcriptional and posttranscriptional levels (8). Promoter variants of the TNF gene are known to affect its transcription (9). Two single nucleotide polymorphisms in this region, more specifically, guanosine $(\mathrm{G})$ to adenosine (A) transition variants at desig-

Received October 5, 2007; accepted March 23, 2008.

Correspondence: S. Nadya J. Kazzi, M.D., Department of Pediatrics, Hutzel Women Hospital, 3980 John R, Detroit, MI 48201; e-mail: nkazzi@med.wayne.edu nated TNF- $\alpha-308$ and TNF- $\beta+250$ [also known as lymphotoxin- $\alpha($ LT $-\alpha+250)]$ reflecting variants at -308 and +250 , respectively, were associated with increased levels of production of TNF- $\alpha$ (10-12). Another G to A transition at position -238 was associated with a decreased transcription of the TNF gene in vitro (13). In this report, we investigated whether haplotypes of TNF gene variants affect levels of TNF- $\alpha$ in TAF specimen of preterm infants at risk of developing BPD. We also examined the relationship between TNF genotypes of haplotypes and risk of BPD and fetal chorioamnionitis.

\section{PATIENTS AND METHODS}

Infants with a BW $\leq 1250 \mathrm{~g}$ were recruited within the first $48 \mathrm{~h}$ of life from the Neonatal Intensive Care Nursery at Hutzel Women Hospital in Detroit, MI. After obtaining an informed consent from the infant's parent(s) or guardian, an EDTA preserved blood specimen $(0.5 \mathrm{~mL})$ was collected for the determination of TNF genotypes. DNA was extracted from peripheral blood mononuclear cells using the Genomic DNA purification Kit (Promega, Madison, WI). Genotypic analysis of TNF- $\alpha$ polymorphic sites [LT- $\alpha+250$ (rs909253), TNF- $\alpha$-308 (rs1800629), TNF- $\alpha$-238 (rs361525)] was performed by using a polymerase chain reaction-restriction fragment length polymorphism technique, as previously described $(12,14,15)$. The diagram in Figure 1 illustrates the method used in generating infants' haplotypes.

TAF samples were collected from ventilated infants at entry into the study and $7,14,21$, and $28 \mathrm{~d}$ later, so long as the infant remained on mechanical ventilation. Whenever the infant needed suctioning, $1.0-1.5 \mathrm{~mL}$ of $0.9 \mathrm{NS}$ was instilled in two aliquots into the infant's endotracheal tube, three to five breaths were delivered with a handbag and the tracheal lavage fluid was aspirated into a sterile aspirating tube (Luki, American Cyanamid Co, CT). The suction catheter was rinsed with a single pass into a 0.9 NS solution. The TAF was centrifuged and the supernatant was separated and stored at $-80^{\circ} \mathrm{C}$ for subsequent analysis. Levels of TNF- $\alpha$ in TAF were measured using a high sensitivity ELISA method that quantifies total TNF (free and bound to soluble receptors) (Quantakine HS human TNF- $\alpha$ system, R\&D Systems, Minneapolis, MN). The sensitivity of the assay for the determination of TNF was 0.062 $\mathrm{pg} / \mathrm{mL}$ with an interassay and intraassay coefficients of variation of $<10 \%$. To correct for the diluting effect of the saline solution used in the tracheal suctioning, the total protein concentration in TAF was determined using bicinchoninic acid method (BCA protein assay, Pierce, Rockfort, IL) and was used for standardization. Values of TNF- $\alpha$ are reported as picogram per milligram of protein. All protein determinations were based on interpolation within the standard curve.

Gestational age was determined from the maternal last menstrual period and/or first or second trimester antenatal ultrasound when available. For pregnant women with limited or no prenatal care, the infants' gestational age

\footnotetext{
Abbreviations: BPD, bronchopulmonary dysplasia; HH, high secreting TNF diplotype; HL, intermediate secreting TNF diplotype; LL, low secreting TNF diplotype; LTA, lymphotoxin alpha; TAF, tracheal aspirate fluid
} 
1
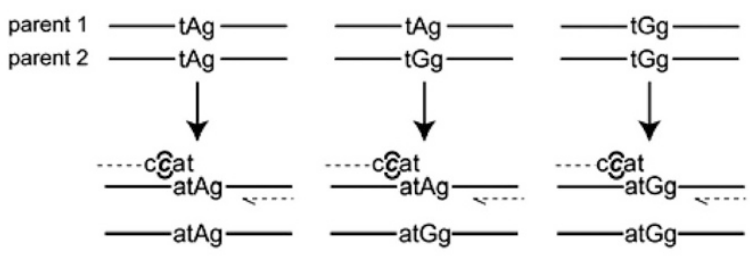

PCR amplification

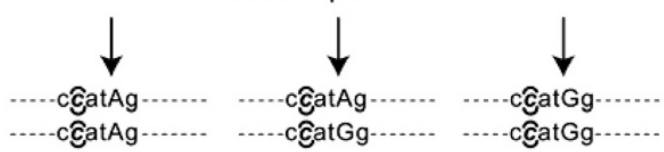

Ncol Restriction Endonuclease Digestion

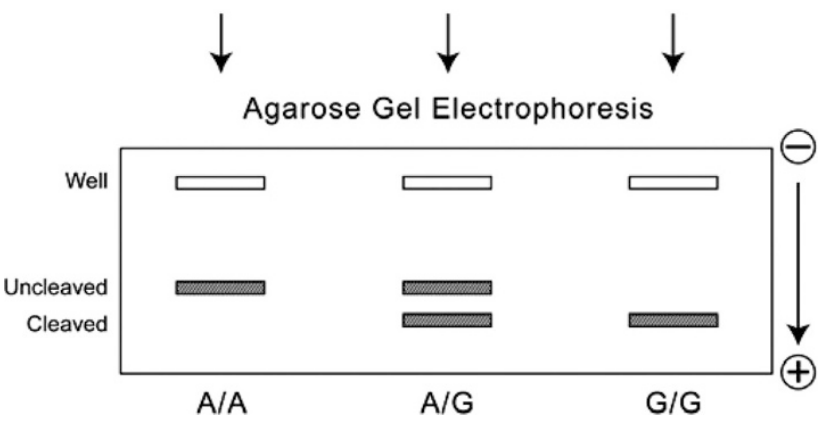

Figure 1. Scheme showing genotyping of two different homozygotes and a heterozygote for a single SNP. DNA from three individuals (1, homozygote $\mathrm{A} / \mathrm{A} ; 2$, heterozygote $\mathrm{A} / \mathrm{G}$; and 3 , homozygote $\mathrm{G} / \mathrm{G}$ ) is shown indicating the SNP state on the two parental copies of the DNA (nucleotide in capital letter indicates the SNP base). Parents are identified as 1 and 2 because it is not possible to identify the paternal and maternal allele. PCR amplification was performed with a mismatched and matched primer. The mismatched $\mathrm{c}$ is encircled and italicized; its presence together with the G state in the SNP yields a product cleavable by the restriction enzyme NcoI. Products were separated by agarose gel electrophoresis and the SNP state identified by the sizes of the products.

was determined by averaging estimates obtained from a late antenatal ultrasound and postnatal assessment using the Ballard examination (16). The diagnosis of fetal chorioamnionitis was based on histologic examination of the placenta (17). The pathologists were unaware of infants' TNF- $\alpha$ levels or genotypes. Symptomatic infants with respiratory distress syndrome were treated with surfactant (Survanta, Ross Laboratories, Columbus, $\mathrm{OH}$ ). The diagnosis of patent ductus arteriosus was confirmed with a two-dimensional Doppler flow echocardiogram. Late onset sepsis was diagnosed in the presence of a positive blood or cerebrospinal fluid culture obtained after $5 \mathrm{~d}$ of age. BPD was defined as dependency on supplemental oxygen at $36 \mathrm{wk}$ postmenstrual age with radiographic evidence of parenchymal lung disease. The study was reviewed and approved by the Institutional Review Board at Wayne State University in Detroit, MI.

Statistical analysis was performed using SPSS 13.5 for Windows (SPSS Inc., Chicago, IL) and with R, a language and environment for statistical computing (version 2.4.0) (18). Haplotype frequencies and probabilities were estimated using the HaploStats package in $\mathrm{R}$ which implements an approach that uses the expectation-maximization algorithm in conjunction with a general linear model approach and can take outcome variables and covariates into account $(19,20)$. An individual has a pair of haplotypes, one from each parent, that together are called diplotype. The diplotypes for individuals homozygous at all, or all but one, of the markers can be assigned unambiguously, i.e., one and only one diplotype is possible for the individual

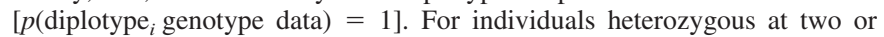
more markers, more than one diplotype is possible. For such individuals, the probability of more than one diplotype is estimated such that the sum of diplotype probabilities is 1 . The TNF- $\alpha$ protein levels were made multivariate normal by a Box-Cox power transformation and were subsequently used as outcome variable in the haplotype estimation. Haplotypes were estimated for all genotyped DNA specimens and stratified by race. Estimation was first performed in the absence of normalized TNF- $\alpha$ levels and subsequently with TNF- $\alpha$ levels as outcome for all days where TAF specimens were available. To stabilize the estimates, HaploStats uses the most common haplotype as the baseline or reference haplotype. The effect of the haplotype on the outcome variable (TNF- $\alpha$ protein levels) with respect to the reference haplotype (the most common haplotype) is indicated by the regression coefficient $(\beta)$. The linear model coefficients were examined to determine which haplotypes were associated with high (H) and which with low (L) TNF- $\alpha$ protein levels. Simplified diplotypes of $\mathrm{H}$ and $\mathrm{L}$ TNF haplotypes were scored on an ordinal scale as 0 (LL), 1 (HL), or $2(\mathrm{HH})$ for infants using the diplotype probabilities for the TNF haplotypes.

Fisher's exact two-sided test was used to compare categorical variables such as BPD and fetal chorioamnionitis. Associations detected by Fisher's exact test were verified using the linear-by-linear association model to ensure that they fit the model of increased risk with an increase in the copy number of high-TNF haplotype (LL, HL, and HH).

\section{RESULTS}

Genotype data were determined on 154 infants. Five infants of Hispanic origin were excluded from the data analysis because of their limited number. Among the remaining infants $(n=149)$, TAF samples were successfully obtained from 96 infants on day 1,59 on day 7, 50 on day 14,55 on day 21 , and 59 on day 28. Characteristics of infants and their hospital course are shown in Table 1. Tumor necrosis factor haplotype frequencies among all infants, African American and white infants are shown in Table 2. We refer to all haplotypes using the nucleotide bases in the chromosome order, e.g., A-G-A [A (LT- $\alpha+250)-\mathrm{G}$ (TNF- $\alpha-308)$-A (TNF- $\alpha-238)]$. The most

Table 1. Infants characteristics and hospital course $(n=149)$

\begin{tabular}{lc} 
Birth weight $(\mathrm{g})^{*}$ & $891 \pm 217$ \\
Gestational age (wks)* & $27 \pm 3$ \\
White/African American $\dagger$ & $34(23 \%) / 115(77 \%)$ \\
Male $\dagger$ & $70(47 \%)$ \\
Fetal chorioamnionitis $\dagger$ & $40(26 \%)$ \\
PROM $\geq 18$ hrs $\dagger$ & $36(24 \%)$ \\
Antenatal steroids $\dagger$ & $116(78 \%)$ \\
Cesarean birth $\dagger$ & $100(67 \%)$ \\
Apgar Score $\leq 5$ at 5 min $\dagger$ & $23(15 \%)$ \\
Ventilatory index at entry into study (VI) $\ddagger$ & $3.0(1.7-6.2)[108]$ \\
PDA $\dagger$ & $62(42 \%)$ \\
Grade 3 or 4 IVH $\dagger$ & $22(15 \%)$ \\
NEC stage $\geq 2 \dagger$ & $21(14 \%)$ \\
Late onset sepsis $\dagger$ & $57(38 \%)$ \\
BPD $\dagger$ & $50(34 \%)$ \\
Survived to hospital discharge $\dagger$ & $112(75 \%)$ \\
\hline
\end{tabular}

$*$ Values are mean $\pm \mathrm{SD}$.

$\dagger$ Values are count (percentage) of infants.

$\ddagger \mathrm{VI}=\mathrm{MAP} \times \mathrm{FiO}_{2}$; values are median (25-75th interquartile range); number of infants in brackets.

Table 2. Haplotype frequencies among infants

\begin{tabular}{cccc}
\hline $\begin{array}{c}\text { Haplotype } \\
\text { LT- } \alpha+250, \text { TNF- } \alpha-308, \\
\text { TNF- } \alpha-238)\end{array}$ & $\begin{array}{c}\text { All infants } \\
(N=149)\end{array}$ & $\begin{array}{c}\text { White } \\
(N=34)\end{array}$ & $\begin{array}{c}\text { African } \\
\text { American } \\
(N=115)\end{array}$ \\
\hline A-A-A & 0.004 & & 0.005 \\
A-A-G & 0.004 & 0.017 & \\
A-G-A & 0.047 & 0.029 & 0.055 \\
A-G-G & 0.513 & 0.689 & 0.453 \\
G-A-A & & & \\
G-A-G & 0.115 & 0.086 & 0.130 \\
G-G-A & 0.014 & & 0.018 \\
G-G-G & 0.302 & 0.179 & 0.339 \\
\hline
\end{tabular}


Table 3. Estimated haplotype frequencies among infants with TAF TNF- $\alpha$ levels on day $7 *$

\begin{tabular}{|c|c|c|c|c|c|c|}
\hline $\begin{array}{c}\text { Haplotype } \\
(\mathrm{LT}-\alpha+250, \text { TNF- } \alpha-308, \text { TNF- } \alpha-238)\end{array}$ & $\begin{array}{l}\text { All infants } \\
(N=58)\end{array}$ & $\begin{array}{l}\text { White } \\
(N=11)\end{array}$ & $\begin{array}{c}\beta \\
\text { coefficient }\end{array}$ & $\begin{array}{l}\text { African American } \\
\quad(N=47)\end{array}$ & $\begin{array}{c}\beta \\
\text { coefficient }\end{array}$ & High/low \\
\hline A-A-A & 0.008 & & & 0.011 & -1.66 & $\mathrm{~L}$ \\
\hline \multicolumn{7}{|l|}{$A-A-G$} \\
\hline A-G-A & 0.039 & 0.046 & 1.587 & 0.036 & 0.191 & $\mathrm{H}$ \\
\hline A-G-G & 0.538 & 0.682 & 0 & 0.506 & 0 & $\mathrm{H}$ \\
\hline \multicolumn{7}{|l|}{ G-A-A } \\
\hline G-A-G & 0.102 & 0.046 & -3.420 & 0.117 & -0.512 & $\mathrm{~L}$ \\
\hline G-G-A & 0.021 & & & 0.028 & -0.300 & $\mathrm{~L}$ \\
\hline G-G-G & 0.293 & 0.227 & 0.921 & 0.302 & $-0.726 \dagger$ & $\mathrm{L}$ \\
\hline
\end{tabular}

The effects of haplotypes on TAF TNF- $\alpha$ protein levels are indicated by the regression coefficients $(\beta \mathrm{s})$.

* HaploStats incorporates genotypic information from the infants without outcome data.

$\dagger p<0.008$ for GGG $v$ s AGG associated TAF TNF- $\alpha$ levels.

$\mathrm{H}$, high secreting haplotype; $\mathrm{L}$, low secreting haplotype.

common TNF haplotype for both African American and white infants was A-G-G and was used as the reference haplotype in all subsequent analyses. The effect of haplotypes on TNF- $\alpha$ protein levels is indicated by the regression coefficients $(\beta \mathrm{s})$ of the linear model (Table 3). Association of TNF- $\alpha$ protein levels with haplotypes was tested for all days $(1,7,14,21$, and 28). On day 7, the G-G-G haplotype was associated with the lowest TAF TNF- $\alpha$ levels relative to the reference A-G-G haplotype among African American infants (Table 3, $p<$ 0.008). The white subgroup of infants was too small to produce stable estimates. Examination of the regression coefficients among African American infants revealed that they were clustered into two groups, those above and below $\beta=0$ for the reference haplotype A-G-G. Haplotypes associated with high levels of TNF- $\alpha$ protein (indicated by $\mathrm{H}$ in Table 3) can be characterized as A-G-X, i.e., only the LT- $\alpha+250$ and TNF- $\alpha-308$ seem to contribute to the elevation in the TNF- $\alpha$ protein levels. Haplotypes associated with low levels of TNF- $\alpha$ protein seem to include mostly those with G allele of LT $-\alpha+250$, although this observation did not hold for the A-A-A haplotype, which had the lowest frequency of all haplotypes among African American infants, and the estimate was derived from two haplotypes only.

We assigned diplotypes, i.e., genotypes of LL, LH, HH pairs of haplotypes to all African American infants $(n=115)$, including those who did not have TNF- $\alpha$ protein levels measured on day 7 , but had levels measured on one or more other days. Diplotype probabilities revealed that for all but five African American infants, the diplotypes were unambiguous (e.g., A-G-G/G-G-G). Of the five infants, only one was ambiguous with respect to the high/low diplotype assignment, because the ambiguity was removed for four infants when simplifying the haplotypes. This infant with ambiguous $\mathrm{H} / \mathrm{L}$ diplotype did not have relevant data on BPD and fetal chorioamnionitis and thus, did not influence the outcome of subsequent analyses.

Sequential changes in actual and normalized TNF- $\alpha$ protein levels plotted according to infants' diplotypes (LL, HL, and $\mathrm{HH}$ ) are depicted in Table 4 and Figure 2, respectively. All three diplotypes demonstrate a rise in TNF- $\alpha$ protein levels from day 1 to 14 . The HH diplotype demonstrates the most rapid rate of increase, the HL diplotype, an intermediate and the LL diplotype the slowest rate of increase. Interestingly,
TAF levels of TNF- $\alpha$ for HL and HH diplotypes peaked at $14 \mathrm{~d}$, compared with the LL diplotype for which TNF- $\alpha$ levels peaked at $21 \mathrm{~d}$. Levels of TNF- $\alpha$ for all three diplotypes returned to very-near baseline levels at $28 \mathrm{~d}$.

Finally, we found no correlation between infants' diplotype status and the development of BPD ( $p=0.54)$; however, fetal chorioamnionitis was significantly associated with the diplotype status (Table 5, $p<0.005$ ). The latter association was maintained when the linear-by-linear association model was applied $(p<0.001)$ indicating that the association was consistent with an additive genetic model in which the risk of fetal chorioamnionitis increases with the number of copies of $\mathrm{H}$ haplotypes in each diplotype. Because fetal chorioamnionitis may affect levels of TNF- $\alpha$, and as a result an infant's diplotype assignment, we estimated haplotype frequencies after adjusting for fetal chorioamnionitis in the linear model. The frequencies estimate, and the betas, change very slightly, not affecting the results.

Because TNF- $\alpha$ measurements were available only for those infants who were intubated and survived the first $28 \mathrm{~d}$ of life, there was a potential that data would be missing selectively by genotype or diplotype. We therefore modeled survival using Cox proportional hazard regression with diplotype as covariate and found no significant effect of diplotype on survival $(p=0.76)$.

\section{DISCUSSION}

Reports of variability in the production of TNF- $\alpha$ in association with three alleles of the TNF gene (LT- $\alpha+250$, TNF$\alpha-308$, and TNF- $\alpha-238)(10-13)$ instigated our study of determining whether haplotypes of these alleles affect TAF levels of TNF- $\alpha$ among ventilated preterm infants at risk of BPD. We speculated that a diplotype of "high secretor" haplotypes of TNF- $\alpha$ might increase an infant's risk of developing BPD. We selected the above-mentioned alleles of TNF and LT- $\alpha$ because they are in linkage disequilibrium and are inherited as haplotypes $(11,21)$. By using diplotypes of haplotypes, we aimed to capture the sum effect of both copies of TNF gene on TAF levels of TNF- $\alpha$. Finally, we measured TAF rather than plasma concentrations of TNF- $\alpha$ because they are better reflective of lung tissue inflammation. 
Table 4. TAF TNF- $\alpha$ levels by diplotype status*

\begin{tabular}{|c|c|c|c|c|c|c|c|c|c|c|}
\hline & \multicolumn{5}{|c|}{ Actual (untransformed) } & \multicolumn{5}{|c|}{ Transformed (power $=-0.06)$} \\
\hline & D1 & D7 & D14 & D21 & D28 & D1 & D7 & D14 & D21 & $\mathrm{D} 28$ \\
\hline \multicolumn{11}{|l|}{ LL } \\
\hline$n$ & 24 & 12 & 9 & 13 & 9 & 24 & 12 & 9 & 13 & 9 \\
\hline Min & 0.11 & 0.44 & 1.11 & 1.23 & 4.12 & -2.36 & -0.84 & 0.10 & 0.21 & 1.36 \\
\hline $25 \%$ & 0.94 & 2.56 & 3.85 & 3.58 & 7.44 & -0.07 & 0.91 & 1.29 & 1.23 & 1.89 \\
\hline Median & 2.85 & 4.40 & 10.04 & 24.84 & 15.52 & 1.01 & 1.41 & 2.15 & 2.92 & 2.53 \\
\hline $75 \%$ & 6.45 & 8.91 & 44.09 & 88.55 & 43.93 & 1.76 & 2.01 & 3.39 & 3.93 & 3.38 \\
\hline Max & 45.13 & 47.74 & 117.93 & 231.33 & 885.02 & 3.41 & 3.45 & 4.15 & 4.64 & 5.57 \\
\hline \multicolumn{11}{|l|}{ LH } \\
\hline$n$ & 26 & 19 & 19 & 18 & 15 & 26 & 19 & 19 & 18 & 15 \\
\hline Min & 0.19 & 1.03 & 0.17 & 1.68 & 1.11 & -1.75 & 0.03 & -1.87 & 0.51 & 0.10 \\
\hline $25 \%$ & 1.65 & 4.54 & 4.78 & 3.98 & 7.85 & 0.49 & 1.44 & 1.49 & 1.28 & 1.93 \\
\hline Median & 3.86 & 10.74 & 11.65 & 17.64 & 17.32 & 1.29 & 2.21 & 2.28 & 2.59 & 2.62 \\
\hline $75 \%$ & 16.92 & 27.99 & 40.28 & 38.14 & 55.33 & 2.60 & 3.02 & 3.30 & 3.27 & 3.57 \\
\hline Max & 111.95 & 78.05 & 200.64 & 94.63 & 163.40 & 4.11 & 3.83 & 4.54 & 3.98 & 4.39 \\
\hline \multicolumn{11}{|l|}{$\mathrm{HH}$} \\
\hline$n$ & 22 & 16 & 12 & 13 & 6 & 22 & 16 & 12 & 13 & 6 \\
\hline Min & 0.25 & 2.78 & 3.27 & 3.52 & 4.35 & -1.45 & 0.99 & 1.14 & 1.21 & 1.41 \\
\hline $25 \%$ & 1.25 & 13.71 & 12.16 & 8.73 & 5.77 & 0.20 & 2.42 & 2.29 & 2.03 & 1.66 \\
\hline Median & 4.93 & 19.92 & 38.01 & 17.59 & 7.93 & 1.52 & 2.73 & 3.23 & 2.63 & 1.93 \\
\hline $75 \%$ & 15.67 & 43.34 & 73.17 & 42.72 & 11.03 & 2.52 & 3.37 & 3.77 & 3.36 & 2.23 \\
\hline Max & 53.02 & 147.30 & 219.88 & 122.83 & 56.18 & 3.53 & 4.31 & 4.61 & 4.18 & 3.58 \\
\hline
\end{tabular}

* TNF- $\alpha$ protein levels in units of pg TNF- $\alpha / \mathrm{mg}$ total protein. The Box and Cox power transformation is identical to log transformation when the power is 0 . Here we have a power close to 0 . The difference between the usual log transformation and the power transformation is that the power transformation reduces both the standard deviations and kurtosis at the expense of a little more skew.

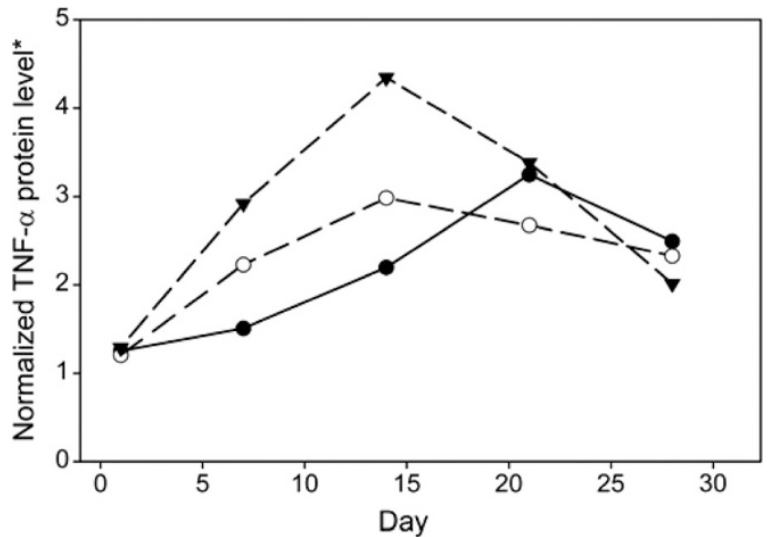

Figure 2. Sequential TAF levels of TNF- $\alpha$ protein among African American infants according to TNF diplotypes: high ( $\mathrm{HH}, \mathbf{\nabla}, n=34)$, intermediate (HL, $\bigcirc, n=48$ ), and low (LL, $\bullet, n=33$ ) secreting. *Data were transformed using Box and Cox power transformation with an exponent of $0.05\left[\left(x^{0.05}-\right.\right.$ 1)/0.05].

Table 5. Fetal chorioamnionitis and TNF diplotypes among African American infants*

\begin{tabular}{lccc}
\hline & \multicolumn{3}{c}{ TNF diplotype } \\
\cline { 2 - 4 } & LL $(\%)$ & HL $(\%)$ & HH (\%) \\
\hline $\begin{array}{c}\text { Chorioamnionitis present } \\
(n=38)\end{array}$ & $5(13)$ & $15(40)$ & $18(47)$ \\
$\begin{array}{c}\text { Chorioamnionitis absent } \\
(n=58)\end{array}$ & $23(40)$ & $23(40)$ & $12(20)$ \\
\hline
\end{tabular}

\footnotetext{
Values are counts (percentage) of infants.

* Fisher's exact test, $p<0.005$; linear by linear association model, $p<$ 0.001 .
}

We found significant variability in the frequency of haplotypes of TNF among African American and white infants. The most common TNF haplotype among all infants was AGG (A allele of LT- $\alpha+250, \mathrm{G}$ allele of TNF- $\alpha-308$, and G allele of TNF- $\alpha-238$, respectively). Among African American infants, significantly lower TAF TNF- $\alpha$ levels were noted on day 7 in association with GGG haplotype compared with AGG haplotype (reference). Both AGA and AGG haplotypes were associated with higher TAF levels of TNF- $\alpha$ on day 7. TAF TNF- $\alpha$ levels increased during the first 2 wk of life among African American infants with the rate of rise and peak levels of TNF- $\alpha$ being highest among infants with a diplotype of "high secreting" haplotypes $(\mathrm{HH})$, followed by a diplotype of "intermediate secreting" (HL), and "low secreting" haplotypes (LL). Interestingly, infants with the LL diplotype had the slowest rate of rise in TAF TNF- $\alpha$ levels reaching a delayed and lower peak at $21 \mathrm{~d}$ compared with infants with $\mathrm{HH}$ diplotype. All TAF TNF- $\alpha$ levels returned to near baseline by $28 \mathrm{~d}$ of the study. Despite significantly affecting TAF levels of TNF- $\alpha$, infants' diplotype status did not seem to affect the risk of BPD. In contrast, the risk of fetal chorioamnionitis increased with increasing number of $\mathrm{H}$ haplotypes in each diplotype.

The frequencies of TNF gene haplotypes in our population are comparable with those reported by other investigators $(22,23)$. We found no report in the literature relating TAF levels of TNF- $\alpha$ to haplotypes or diplotypes of the TNF gene. Investigators who explored associations between haplotypes of TNF gene, levels of TNF- $\alpha$ and disease outcome reported variable results, some of which could be attributed to differences in pathogenetic mechanisms (23-29). Some, similar to our findings with BPD, noted an effect on levels of TNF without an association to underlying disease risk (24-26). Increased beryllium-stimulated BAL cell TNF- $\alpha$ levels were observed among patients with chronic beryllium disease who 
had TNF haplotype -1031T, -863C, -857C, -307G, -237G without a significant association with measures of disease severity (24). Elevated levels of TNF- $\alpha$ secretion by activated mononuclear cells were associated with TNF haplotype [-238G, -308A, LTA (AspHI) C, LTA NcoI G] without a difference in TNF- $\alpha$ or LT- $\alpha$ production between patients with inflammatory bowel disease and healthy controls (25). Three TNF haplotypes defined by eight SNPs within the TNF gene region were associated with lower levels of expression of TNF- $\alpha$ without affecting the risk of developing schizophrenia (26). Other investigators reported effects of TNF haplotypes on levels of TNF and disease risk and or outcome (27-29). Increased serum IgE and TNF- $\alpha$ levels were associated with an increased risk for asthma among Indian individuals homozygous for TNF haplotype GATCCG [LT- $\alpha$ (His51Pro), LT- $\alpha$ (Thr60Asn), TNF- $\alpha-1031 \mathrm{C},-863 \mathrm{~A},-857 \mathrm{C},-308 \mathrm{G}]$ (27). A better response to chemotherapy and a greater progressionfree and overall survival were reported among patients with non-Hodgkin's lymphoma carrying a low-risk TNF haplotype, i.e., containing less than two adenine alleles of TNF- $\alpha-308$ or LT $-\alpha+250$ that were associated with high plasma levels of TNF- $\alpha$ or LT- $\alpha$, respectively (28). Higher nasal levels of TNF- $\alpha$ were observed during acute wheezing episodes among infants with a TNF haplotype containing one or two LT$\alpha+252 \mathrm{~A}$ alleles (29). In our study, we found that the risk of fetal chorioamnionitis increased with increasing number of high secreting TNF haplotype. Finally, a multicenter study among adult patients with severe sepsis and septic shock failed to demonstrate an association between TNF genotypes (TNF- $\alpha$ 308, TNF- $\alpha-238$, LTA +249 , and LTA +365 ), plasma levels of TNF- $\alpha$ and risk, severity or outcome of sepsis (23).

Our findings of a lack of association between diplotypes of TNF and BPD suggest that mechanisms other than prolonged inflammation may be important in the development of BPD. In support of this argument is our observation that, following an initial rise, tracheal TNF- $\alpha$ levels returned to baseline by $28 \mathrm{~d}$. It is likely that, beyond the first month of life, the extent of disrupted lung development, airway and vascular damage is the main determinant for the development of BPD (30).

Using genotype analysis of individual alleles of TNF, our group previously reported a decreased risk and severity of BPD in association with the adenine allele of TNF- $\alpha-238$ (rs361525) (31). In this study, we examined the relationship between diplotypes of haplotypes defined by level of TNF- $\alpha$ secretion and BPD. The diplotypes did not replicate the association of SNP (rs361525) with BPD. The comparisons and results are different. Either or both may be true associations. We speculate that the previous association of BPD with rs361525 may be due to a different mechanism, not dependent on the secretion level of TNF- $\alpha$. Replication studies are essential to validate the results.

On the other hand, our diplotype analysis confirmed a rising risk of fetal chorioamnionitis with increasing number of high secretor TNF haplotypes. These findings are in agreement with an earlier report in which we described an increased risk of fetal chorioamnionitis in the presence of A allele of LT$\alpha+250$, a fixed component of high secretor diplotype as defined in this study (17). Other investigators reported a similar association between severity of fetal chorioamnionitis and levels of TNF- $\alpha$ (32).

In summary, by using an analysis of genotypes of haplotypes, we were able to demonstrate the presence of different genotypes of TNF in association with various levels of production of TNF- $\alpha$. Specifically, genotypes of TNF consisting of haplotypes containing the A allele of LT- $\alpha+250$ and $\mathrm{G}$ allele of TNF- $\alpha-308$ were associated with higher levels of secretion of TNF- $\alpha$. The absence of an association between genotypes of TNF and risk of BPD highlights the difficulties encountered in clinical practice in delineating the contribution of individual risk factors to multifactorial diseases.

\section{REFERENCES}

1. Speer CP, Groneck P 2000 Inflammatory mediators in neonatal lung disease. In: Bland R, Coalson J (eds) Chronic Lung Disease in Early Infancy. New York: Marcel Dekker, pp 147-157

2. Jónsson B, Tullus K, Brauner A, Lu Y, Noack G 1997 Early increase of TNF- $\alpha$ and IL-6 in tracheobronchial aspirate fluid indicator of subsequent chronic lung disease in preterm infants. Arch Dis Child Fetal Neonatal Ed 77:F198-F201

3. Eigler A, Sinha B, Hartmann G, Endres S 1997 Taming TNF: strategies to restrain this proinflammatory cytokine. Immunol Today 18:487-492

4. de Dooy JJ, Mahieu LM, van Bever HP 2001 The role of inflammation in the development of chronic lung disease in neonates. Eur J Pediatr 160:457-463

5. Kelly M, Kolb M, Bonniaud P, Gauldie J 2003 Re-evaluation of fibrogenic cytokines in lung fibrosis. Curr Pharm Des 9:39-49

6. Molvig J, Baek L, Christensen P, Manogue KR, Vlassara H, Platz P, Nielsen LS, Svejgaard A, Nerup J 1988 Endotoxin-stimulated human monocyte secretion of interleukin 1, tumor necrosis factor alpha, and prostaglandin E2 shows stable interindividual differences. Scand J Immunol 27:705-716

7. Westendorp RG, Langermans JM, Huizinga TW, Elouali AH, Verweij CL, Boomsma DI, Vandenbroucke JP 1997 Genetic influence on cytokine production and fatal meningococcal disease. Lancet 349:170-173

8. Sariban E, Imamura K, Luebbers R, Kufe D 1988 Transcriptional and posttranscriptional regulation of tumor necrosis factor gene expression in human monocytes. $\mathrm{J}$ Clin Invest 81:1506-1510

9. Goldfeld AE, Strominger JL, Doyle C 1991 Human tumor necrosis factor alpha gene regulation in phorbol ester stimulated T and B cell lines. J Exp Med 174:73-81

10. Kroeger KM, Carville KS, Abraham LJ 1997 The -308 tumor necrosis factor- $\alpha$ promoter polymorphism effects transcription. Mol Immunol 34:391-399

11. Wilson AG, Symons JA, McDowell TL, McDevitt HO, Duff GW 1997 Effects of a polymorphism in the human tumor necrosis factor alpha promoter on transcriptional activation. Proc Natl Acad Sci USA 94:3195-3199

12. McArthur JA, Zhang Q, Quasney MW 2002 Association between the A/A genotype at the lymphotoxin-alpha +250 site and increased mortality in children with positive blood cultures. Pediatr Crit Care Med 3:341-344

13. Kaluza W, Reuss E, Grossmann S, Hug R, Schopt RE, Galle PR, Maerker-Hermann $\mathrm{E}$, Hoehler T 2000 Different transcriptitonal activity and in vitro TNF- $\alpha$ production in psoriasis patients carrying the TNF- $\alpha-238$ A promoter polymorphism. J Invest Dermatol 114:1180-1183

14. Day CP, Grove J, Daly AK, Stewart MW, Avery PJ, Walker M 1998 Tumor necrosis factor-alpha gene promoter polymorphism and decreased insulin resistance. Diabetologia 41:430-434

15. Quasney MW, Bronstein DE, Cantor RM, Zhang Q, Stroope C, Shike H, Bastian JF, Matsubara T, Fujiwara M, Akimoto K, Newburger JW, Burns JC 2001 Increased frequency of alleles associated with elevated tumor necrosis factor- $\alpha$ levels in children with Kawasaki disease. Pediatr Res 49:686-690

16. Ballard JL, Khoury JC, Wedig K, Wang L, Eilers-Walsman BL, Lipp R 1991 New Ballard Score, expanded to include extremely premature infants. J Pediatr 119:417423

17. Kazzi SN, Jacques SM, Qureshi F, Quasney MW, Kim OU, Buhimschi IA 2004 Tumor necrosis factor- $\alpha+250$ is associated with the presence and severity of placental inflammation among preterm births. Pediatr Res 56:94-98

18. R Development Core Team 2006 R: A Language and Environment for Statistical Computing. Vienna, Austria: R Foundation for Statistical Computing

19. Schaid DJ, Rowland CM, Tines DE, Jacobson RM, Poland GA 2002 Score tests for association between traits and haplotypes when linkage phase is ambiguous. Am J Hum Genet 70:425-434

20. Schaid DJ 2004 Evaluating associations of haplotypes with traits. Genet Epidemiol 27:348-364

21. Hajeer AH, Hutchinson IV 2001 Influence of TNF $\alpha$ gene polymorphisms on TNF $\alpha$ production and disease. Hum Immunol 62:1191-1199

22. Baxter N, Sumiya M, Cheng S, Erlich H, Regan A, Simons A, Summerfield JA 2001 Recurrent miscarriage and variant alleles of mannose binding lectin, tumour necrosis factor and lymphotoxin $\alpha$ genes. Clin Exp Immunol 126:529-534

23. Gordon AC, Lagan AL, Aganna E, Cheung L, Peters CJ, McDermott MF, Welsh KI, Holloway P, Hitman GA, Piper RD, Garrard CS, Hinds CJ 2004 TNF and TNFR polymorphisms in severe sepsis and septic shock: a prospective multicentre study. Genes Immun 5:631-640 
24. Sato H, Silveira L, Fingerlin T, Dockstader K, Gillespie M, Lagan AL, Lympany P, Sawyer RT, duBois RM, Welsh KI, Maier LA 2007 TNF polymorphism and bronchoalveolar lavage cell TNF- $\alpha$ levels in chronic beryllium disease and beryllium sensitization. J Allergy Clin Immunol 119:687-696

25. Bouma G, Crusius JB, Oudkerk Pool M, Kolkman JJ, von Blomberg BM, Kostense PJ, Giphart MJ, Schreuder GM, Meuwissen SG, Pena AS 1996 Secretion of tumour necrosis factor alpha and lymphotoxin alpha in relation to polymorphism in the TNF genes and HLA-DR alleles. Relevance for inflammatory bowel disease. Scand J Immunol 43:456-463

26. Shirts BH, Bamne M, Kim JJ, Talkowski M, Wood J, Yolken R, Mimgaonkar VL 2006 A comprehensive genetic association and functional study of TNF in schizophrenia risk. Schizophr Res 83:7-13

27. Sharma S, Sharma A, Kumar S, Sharma SK, Ghosh B 2006 Association of TNF haplotypes with asthma, serum IgE levels and correlation with serum TNF- $\alpha$ levels. Am J Respir Cell Mol Biol 35:488-495
28. Warzocha K, Ribeiro P, Bienvenu J, Roy P, Charlot C, Rigal D, Coiffier B, Salles C 1998 Genetic polymorphisms in the tumor necrosis factor locus influence nonHodgkin's lymphoma outcome. Blood 91:3574-3581

29. Bilolikar H, Nam AR, Rosenthal M, Davies JC, Henderson DC, Balfour-Lynn IM 2005 Tumor necrosis factor gene polymorphisms and childhood wheezing. Eur Respir J 26:637-646

30. Jobe AH, Bancalari E 2001 Bronchopulmonary dysplasia. Am J Respir Crit Care Med 163:1723-1729

31. Kazzi SN, Kim O, Quasney MW, Buhimschi I 2004 Polymorphism of tumor necrosis factor- $\alpha$ and risk and severity of bronchopulmonary dysplasia among very low birth weight infants. Pediatrics 114:e243-e248

32. Døllner H, Vatten L, Halgunset J, Rahimipoor S, Austgulen R 2002 Histologic chorioamnionitis and umbilical serum levels of pro-inflammatory cytokines and cytokine inhibitors. BJOG 109:534-539 